\title{
GLOBALISATION PLUS COMPARATIVE AND INTERNATIONAL EDUCATION: TOWARDS A THEORY OF THE CONFLUENCE
}

\author{
Emefa Amoako \\ Department of Education, University of Oxford
}

\begin{abstract}
This paper attempts to contribute to ways by which confluence, referring to a meeting point for the different agents to cooperate and communicate on education policy processes, can be understood. Pertinent national education policies in countries receiving aid, in particular, are formed and implemented in a complex nexus. Cultural and context sensitivity can be stimulated through a thorough understanding of this confluence, which subsequently can enable the different policy agents, which function at this meeting point, collaborate to alleviate some of the educational challenges. Comparative and international education, in this respect, has a significant role to play.
\end{abstract}

\section{Rationale: Effects of Globalisation on Policy-Making in National Contexts}

There is the need to understand what national policy-making means in aid recipient countries, and in the process, it is essential to understand the influence of globalisation on policy-making in these national contexts. Globalisation requires a reconsideration of

\begin{abstract}
...how...policies are formed, shaped and directed...[and] the key problem then becomes understanding the nature of globalisation in ways that enable one to trace more precisely, how, and with what consequences, it affects national policies, what is the nature and extent of their influence (Dale, 1999, p.1).
\end{abstract}

In applying Bourdieu's "thinking tools", (i.e. habitus, practice, capitals and fields) to policy studies, Rawolle and Lingard (2008) argue that in this era of globalisation cross-field effects (the influence of practices in the policy field on actors in alternative fields) can be a means of categorising, researching and defining policy effects. Both argue in terms of "an emergent global education policy field" and attempt to examine some of the means by which such a field influences national education policy. While their work acknowledges the connection between the global and national policy fields, it does not examine this link empirically. They articulate the need for studies that will investigate this intersection when they argue that:

...research is required now to understand the nature of this emergent global education policy field, its agencies and relationships, associated cosmopolitan policy habitus and practices, and cross-field effects with national education policy field mediated by national capital (p.733).

The current paper is one attempt to contribute to ways by which this global and national education policy nexus referred to as the confluence could be understood. Part 1 introduces the argument, states its rationale and briefly mentions the research procedures. Part 2 briefly outlines the ideas and features that frame the confluence, while acknowledging the importance of its globalisation dimension. It then highlights and examines globalisation. Part 3 illustrates how globalisation frames the confluence by drawing on findings of a study into the shaping of Ghana's ESP. Part 4 then concludes by arguing the significance of the confluence in education policy processes.

\section{Research Approach}

My analysis is based on a study that utilised a qualitative research design, and adopted the interpretative approach of investigating actions and behaviour that emerged from the MoE-donor agencies' interactions and their shaping of the ESP in their natural setting. It employed the non-probability sampling (Merriam, 1988; Punch, 1998; Robson, 1993) because the nature of the research questions and the qualitative strategy required this sampling approach. In other words, sampling was done in a consciously purposeful manner. The MoE, the UK Department for International Development (DFID), the United States Agency for International Development (USAID), the World

${ }^{1}$ Correspondence can be directed to: emefa.amoako@attainingthepeak.org 


\section{EMEFA AMOAKO}

Bank and UNICEF were purposefully identified and selected through purposive, snowball and theoretical sampling methods (Punch 1998; Robson 1993; Strauss \& Corbin, 1990). ${ }^{1}$

The research participants included key actors from the MoE and donor agencies involved on the scene of educational aid delivery in Ghana in the past and present. Though the study's focus was on a current phenomenon, the ESP (2003-2004), it was necessary to situate it in a historical context. Its formulation began in 2002 and, in principle, ended in 2003, although plans for the process were laid down by late 2001 . Therefore, the MoE officials in Ghana who interacted with these selected donor agencies, were identified and interviewed, as were individuals or groups who had worked or were working for them and were interested in the ESP in Ghana; and any other individuals who had been or were involved with the MoE-donor interactions with regards to the shaping of the ESP. The main settings within which participant observation occurred, which included events organised around the ESP such as MoE-donor meetings, Education Sector Annual Review (ESAR) sessions and workshops were also purposively sampled, as were documents that were connected to them. While analysis was largely data-led, existing theoretical notions and analytic frames of policy, globalisation among others in the literature were drawn upon and employed as lenses to interpret the primary findings.

\section{Framing Ideologies: Factors that Shape National Policy Spaces \& Texts}

We now turn to the conceptual framework that defines this meeting point, the confluence. To reiterate the points made above: 'external' ideologies and 'internal' ideologies (they may not always be vastly different) meet in a conceptual space (the confluence of ideas, actions and agents) and it is here where educational policies are ultimately shaped. So, what are the ideologies or policy ideas, actions and agents that flow from the outside into the policy spaces of aid recipient or developing countries, and what and who are the carriers of these ideas? Educational ideologies are carried into the policy environment of developing countries conceptually through economic or cultural globalisation, and more physically through foreign aid by donors. They are not, for obvious reasons, referred to as ideologies, but the positions or stances adopted viz a viz educational development are embedded in the negotiation of aid agreements. Indeed, to mask any sense of an ideology, the notion of 'partnership' is used to seek a consensus of ideas. This notion is contested and critics of the notion of partnership in aid often highlight the unequal status of the donor-recipient relationship and evoke the notion of unequal power. Indeed, the confluence at which national policy processes occur are framed by foreign aid, partnership, power and globalisation processes. Moreover, globalisation as a phenomenon is seen as instrumental in the other three processes. Understanding its processes and how it equally characterises and flows into and shapes the confluence will help to clarify a national policy context (UNESCO, 1999). I shall use the case of Ghana's ESP to exemplify.

\section{Globalisation}

Very pertinent to understanding the complexities that inhabit foreign aid donor-recipient interactions and their ramifications for education policy processes is coming to grips with the phenomenon of globalisation, which engenders power asymmetries that in turn shape education policies. Globalisation processes are among the influential factors that form the confluence, where donors, recipients and their ideas and actions meet and national policies are shaped. This section argues that current processes of globalisation maintain and engender economic and political inequalities between developed countries, often the foreign aid donors, and the developing countries, mostly the recipients. As a result, the former are able to significantly influence national education policy processes of the latter. The section examines the notion of globalisation while tracing its interconnectedness with education in developing countries such as Ghana.

According to a report published by the International Working Group on Education (IWGE), presently, globalisation and its processes are continually influencing the education agenda, "[shaping] the way in which aid is delivered to clients, and [guiding] the channels by which donors, governments and others in the development process interact" (IWGE/UNESCO, 1999, p.17). Therefore, in examining the nature and scope of the connection between international donor agencies and education policy development at the level of the recipient nation-state, a diligent probing of the growing scholarship on globalisation and education is necessary (Henry et al., 2001). For Stromquist $(2002)^{2}$ an analysis of how globalisation influences education demands a definition of the features of the former, an understanding of the powers that generate its processes and interconnected consequences, an evaluation of its results not only in terms of economic growth and affluence, but also its positive and negative social effects (the winners and losers), what Petras (1999) calls distributive outcomes.

Globalisation is a multifaceted phenomenon that defies simple definition because it lends itself to different perceptions depending on which of its distinct features are being examined and which disciplinary lens is applied. According to Stromquist (2002), some analysts stress its technological elements focusing on its capacity for spatial and temporal constitution as well as its ability to reorganise social links, while others are interested in how its dynamics trigger huge flows of persons and information, which in turn shape a cultural hybridity where the 
national/local and the global intersect. She further observes that a number of analysts also examine its sociopolitical consequences, "primarily on developing countries, by and large the losers of globalization" (2) as well as challenge the political powers that originally and constantly sculpt it. Crucial is Stromquist's (2002, p.16) assertion that in developing countries particularly, the effect of globalisation on education would be felt mainly:

\begin{abstract}
...through the uncontested adoption of initiatives in developed countries along such lines as decentralization, privatization, the assessment of student performance, and the development of tighter connections between education and the business sector. In this process of adoption, the influence of international lending and development institutions, as carriers of globalizations, is clearly discernable.
\end{abstract}

Thus, education policy frameworks such as those by the World Bank supported by other donors mirror significantly the "economic globalisation agenda" (Jones \& Coleman, 2005, p.38). Moreover, before foreign aid is delivered, donor states demand as a prerequisite that recipient states embrace World Bank policies and strategies (Elson \& McGee, 1995; Stromquist, 2002).

\title{
Globalisation Framing the Confluence
}

To exemplify the above, this section outlines some of the findings of the study on which this paper is based. Using some of the evidence from 53 interviews, over 100 documents and observations recorded in field notes, this article provides some of the findings to address how the policy text (the ESP) is shaped when the national government (i.e., Ministry of Education [MoE]/Government of Ghana [GoG]) meet (selected) foreign donors. It also provides insights on how the interactions between the national government and the foreign donors might be characterised theoretically.

In an attempt to broadly address both at a more theoretical level, this paper discusses the main findings of the study in relation to the existing literature on globalisation. It considers the implications of external and internal ideologies generated by globalisation processes for education policy-making in the intersection between the global and national spheres. It weaves part of the account of the confluence, the meeting point of these ideologies, ideas, agents and actions of the MoE and selected donors where the ESP was shaped.

The paper argues that policy formulation in aid dependent developing countries is a process influenced by the dynamics of globalisation factors. Simultaneously, these factors drove and were embedded within the ESP shaping process. The development of the ESP 2003 in Ghana is a policy perceived in this study more as a process than a product. This paper essentially seeks to define if the process of the ESP and the MoE-donor interactions that shape it reflect elements of globalisation. And if so, do they shape the ESP and what are the implications?

\section{The ESP Production \& Globalisation}

The section argues that the ESP formulation process was influenced by globalisation through donors who were often the carriers of its elements and the architects and leaders of its process. The ESP was an outcome of a policy formulation process conceptually perceived as a confluence of interactions of aid donors and the MoE and their rivers of ideas and actions. It may represent a product, but it can also be seen as a process. As a process, the ESP mapped the contexts of policy text production and influence as a meeting point of external and internal or global and national ideas, actors and actions (Ball, 1994). This confluence was national but became globalised in the process. The section demonstrates how elements of globalisation, such as the Poverty Reduction Strategy Papers (PRSPs), Millennium Development Goals (MDGs) and Education for All (EFA) goals (which I call the non-negotiables) along with promptings and pressures from donors infiltrated the ESP process. It also shows how these elements led to the narrowing down of the educational policy priorities of Ghana and even their distortion to a certain degree. Findings suggest a policy imposition, illustrated through expressions of globalisation as imperial and colonial. However, it is worth noting that paradoxically, the MoE sometimes mitigated this imposition of the non-negotiables through the support of some donors. Findings suggested that Ghana's education sector had experienced an encounter between external/global and internal/national ideologies in the form of ideas and actions of international donor/lender agencies and of the MoE/GoG in their interactions, which tended to shape Ghana's education policies. The study of the development of the ESP has offered an opportunity to discuss this encounter and its implications for a national policy.

First, the findings indicated that the shaping of the ESP revealed national contexts of policy influence and production which integrated the global (Ball, 1994; Bowe et al., 1992; Lingard \& Ozga, 2007). In other words, the process was located on the cusp of the global and national (Lingard, 1996; Taylor et al., 1997; Vidovich, 2001). This means it transcended a state-controlled perspective and reached into the international/global sphere, which in turn seemed to embed the elements of globalisation in the national (Apple, 1989; Ball, 1994; Bowe et al., 1992; Dale, 1989; Ozga, 1990). The global dimension of the ESP process was ensured and demonstrated by virtue of donor- 


\section{EMEFA AMOAKO}

initiated global policy frameworks. For example, as findings suggested, donors occupying the driving seat ensured that the MoE prioritised policy areas that were emphasised in global policy documents of PRSPs, EFA goals and MDGs, such as girl-child education and universal primary education (UPE). For this reason, the ESP declared that "in view of the GPRS and EFA initiative, the basic education sector, particularly primary schooling is a priority of the Ministry of Education" (ESP I, 2003, p.4). Donor agencies such as UNICEF, DFID and USAID, for instance, would only agree to provide funding if an educational programme was MDG-related. Findings suggested that DFID and the World Bank were working closely together because both were committed to achieving the MDGs. Another example was the World Bank and USAID focusing their funding on HIV/AIDS and health education. Thus, global/transnational policies such as the EFA goals, MDGs, PRSPs were recalibrated to produce the ESP. The global policy frameworks which guided the ESP shaping process, in other words, the treasury of the non-negotiables, within which the MoE was obliged to interact with donors, consolidated the global. These were frameworks also defined by other studies as an "international requirement" (King, 2007, p.359) or as "requirements in the softer sense of 'urgings' or pressures linked with promises of funding" (Little, 2008, p.50). These urgings or pressures were exemplified in the promptings, conditionalities or undertakings (See Amoako, 2009), which the MoE received from donors to shape the ESP, a mechanism for the delivery of educational aid. They represented global requirements and also reflected the form of power, which donors exercised over the MoE (ibid.). Through their identity as agents of globalisation processes, enacted through financial and technical assistance, pressure on and policy dialogue with the MoE, donors appeared to have led the designing of the ESP and guaranteed its globalised character. Hence, it could be stated that education policy frameworks prescribed to aid dependent countries like Ghana mirrored significantly the "globalisation agenda" driven by donors (Jones \& Coleman 2005, p.38).

Second, donors' financial assistance/strength, the seemingly donor knowledge authority and the more or less weak nature of the financial and management capacity of the MoE/GoG secured donor dominance and led to the integration of the elements of globalisation in the ESP process. The study discovered that although the ESP represented a means by which the MoE could assume leadership in its future interactions with donors, its development was more donor-led than MoE-led because of the above global "pressures", which the MoE had to yield to, due to its fragile financial base and technical capacity. For example, several interviews suggested that because the largest finances that ensured the delivery of education to the beneficiaries came from donors and not from the MoE/GoG, the former carried a lot more influence than the latter. It was acknowledged in interviews and documents that the greater portion of finances expended on the ESP formulation process was provided by DFID while UNICEF, the World Bank and USAID also offered technical assistance. MoE-officials maintained that due to the significant amount that donors provided because of the weak financial capacity of the MoE/GoG, the latter had to conform to the donor priorities. The following quote could be said to sum up their view:

Because of the amount of money they provide they are able to force us to move in a certain line even in terms of allocation of resources. There has been this fight...They remind us that we've signed up to the MDGs. Gender parity- we were forced to adopt.

(MoE-GES Official).

The next quote also could be considered a summary of the views of several donor and MoE officials about the influence that donors wielded in their interactions with the MoE/GoG:

So who is financing education? Our funding is. Because all the money that is generated by Ghana is spent on salaries and administration, our money comes in to help improve the quality of services. So we exert an influence because we are the people that make a difference and actually this puts us in a position of having some influence, having real influence.

(Donor Official).

Another example was the acknowledgement by some MoE officials that despite the MoE-donor partnership in principle, donors employed triggers and conditions tied to their funding to ensure that the MoE conformed to donor agendas.

Nevertheless, policy struggles characterised the shaping of the ESP through the MoE-donor interactions although the MoE eventually conformed to donor agendas. This implied that some national policy priorities contested with the donor-initiated global policy interests. For example, findings suggested that during an ESAR session, while some donors with sole interest in UPE cautioned the MoE/GoG against spending more on secondary and tertiary education, some MoE officials equally reminded the former that post-basic education also needed investment. This contestation was further demonstrated in a white paper published after the production of the ESP, which did not only emphasise UPE but also technical/vocational, secondary and tertiary education. Yet, funds 
allocated to secondary and tertiary education were only made possible because the World Bank and the Spanish Government agreed to support the MoE/GoG. Another example of this contestation was shown in the MoE-donor interactions around the policy issue of girl-child education. While the MoE attempted to argue against prioritising it because, according to a number of MoE officials, a policy on access to education for the disadvantaged could cater for it, donors insisted on its prioritisation. Also, the views of some MoE officials conflicted with donor-initiated global policy priorities such as HIV/AIDS and health education of the World Bank and USAID. These views were about the importance of delegating the responsibility of this form of education to the appropriate institutions (e.g. Ministry of Health) and not making it the responsibility of the MoE because it burdened the MoE and diverted it from its core duty of providing good quality education. The MoE sometimes voiced its own national priorities, which were occasionally heeded by one or two donors, but on the whole donor-initiated global priorities dominated due to the significant financial dependence of the MoE on donors.

The implication of the above findings is that the financial capacity of the MoE/GoG or Ghana in relation to the global economy would determine the extent to which they would or would not yield to these global pressures that donors purveyed during the ESP formulation process. Lingard and others (2005, p.766) drawing on Bourdieu argued that, "the amount of 'national capital' possessed by a given nation within these global fields is a determining factor in the spaces of resistance and degree of autonomy for policy development within the nation". The autonomy of the various countries is influenced through diverse means. As Jayasuriya (2001, p.444, quoted in Lingard et al., 2005 , p. 766) suggests, "the focus should not be on the content or degree of sovereignty that the state possesses but the form that it assumes in the global economy".

It could be argued that unlike nation-states like the UK and the USA in the developed world, a developing country such as Ghana does not occupy a privileged economic and dominant position in the intersection between the state and the world in order to secure the advantages of the globalisation processes. The former possess bilateral donor ability with the support of international financial institutions (IFIs), such as the World Bank and the International Monetary Fund (IMF), and so are in a position to dictate the rules of how other countries, particularly the aid dependent ones, are to interact with the global economy and global entities, such as international/transnational policies, institutions and contexts. These international/global policies might influence national policies in developed countries too, but donors' influence in shaping them is significant.

The nation state in the developing world seemed to have less influence on global/international policy processes (Moutsios, 2008, 2009; Stromquist, 2002). While this paper suggests that the analyses of national policy processes should incorporate an extension of the individual nation-state to the global milieu, it contends that some nationstates are more powerfully positioned than others (ibid.). The effect of globalisation is undermining the autonomy of all states, but some states and their institutions are potentially more powerfully positioned than others. The powerfully positioned states exercise more authority over their national education policies than those that are not (ibid.). In this case, since Ghana, an aid dependent country and, therefore, its MoE/GoG were not powerfully positioned politically and economically in the globalisation geography, they did not have any significant influence on the global policy processes and also did not often exercise full control over the shaping process of the ESP (ibid.). Ghana did not compare with powerful nation states such as those in the industrialised world and therefore, was made powerless before an overpowering force (Stromquist, 2002). The main issue about coming to grips with globalisation is to attempt to decipher the means by which it influences national policies (Dale, 2007). It is true that globalisation has not rendered the nation state archaic or non-existent but seems to have transformed the state's policy processes and disabled its capacity for independent policy-making (ibid.). It is, therefore, untenable to assert that some nation states, at least, "have not been rendered impotent in the face of an overwhelming challenge, much less replaced by it..." (ibid. 48). As Stromquist $(2002$, p.8) observed "...many of these international bodies faithfully reflect interests of the major industrialized countries". Dale $(2007$, p.51) brings to the notice of the reader that "the existence of this common ideology demonstrates clearly that though developed countries may have individually ceded some of their national political capacity to international organizations, they have done so voluntarily, in order to maintain their own privileged positions in the world economy..." Indeed, these were the privileged positions that aid recipient countries like Ghana did not occupy (Stromquist, 2002).

As a result of the above, this paper argues that since Ghana did not occupy such privileged positions, it had lost its independent policy making capacity. Moreover, through the shaping of the ESP, which expressed elements of globalisation, the MoE faced a challenging force that distorted its educational policy priorities through a narrowing down process. For example, as findings suggested, donors were more interested in funding UPE than secondary and tertiary education. While it is fair to state that though the global dimension of the ESP was not necessarily disadvantageous to Ghana's education policy development, it often restricted the country's priorities to its parochial interests such as UPE despite the need of the country for more comprehensive priorities regarding primary, secondary, technical/vocational and tertiary education. For instance, findings suggested that, as soon as the ESP was developed, the MoE/GoG published a white paper that highlighted secondary, tertiary and vocational 


\section{EMEFA AMOAKO}

education as additional priorities while the ESP was more biased towards UPE.

This paper, therefore, challenges the assertion in Cornell's (2007, p.111) OECD study that "global programmes funding priorities correspond well with objectives set out in Ghana's national plans and strategies". Findings suggested how forms of power led donors to set the policy agenda and minimise certain national priorities such as secondary and tertiary education, a neglect that was met with indignation from a section of the MoE officials. A situation such as this is sometimes referred to as policy for and by a country (King, 2007). Thus, contrary to other perspectives (Cornell, 2007), the study's findings suggested that funds generated by the EFA/FTI, a global programme, may have led to a distortion of Ghana's education priorities. (See Takyi-Amoako, 2012 for a detailed examination of this point).

The distortion of the MoE priorities was put succinctly by a donor official:

"I think systems are being distorted by donors like ourselves, because we carry a lot more influence than the Government... I think...mostly what we say carries much greater weight and we can influence policies, strategies."

(Donor Official).

Through the culture of pulling examined in the study on which this paper stands, which occurred because of the donor practice of earmarking support and tying aid, the distortion of MoE priorities, which culminated in the fragmented approach to education management, was significantly exemplified. For example, as one donor official put it, "...It stops them [the MoE] from taking a more steady view and approach to development..." (Donor Official, 2003). Indeed, the incidence of tying aid absolutely to particular policies or policy interests represents a potent way in which donors make recipients conform with global or donor agendas (Kuder, 2005). The global policy frameworks (the non-negotiables, or "pressures") within which the MoE was obliged to interact with donors reproduced the donor-designed global policy priorities within the Ghana national context. It manipulated as well as predetermined the national priorities of the ESP. This situation could also be referred to as trade-offs between national agenda and international donor priorities (King, 2007).

The ESP shaping process was perhaps akin to policy imposition (Dale, 1999). It was a process that employed the global policy systems obliging Ghana or the MoE/GoG to accept prescribed policies such as the PRSP (GPRS), EFA goals, and MDGs from supra-national bodies and international aid organisations like the World Bank, DFID, USAID and UNICEF through the process of leverage. In this sense and in the words of Dale (1999) "the locus of viability", the body which determined the feasibility of the ESP was not national but international. For instance, this study discovered that the ESP and Ghana's Proposal for EFA/FTI had to be endorsed by the donor community before they could attract donor funding. Donors' apparent knowledge authority and their frequent complaints that the level of management and technical skills that the MoE possessed was too low also guaranteed the elements of globalisation in the ESP process and ensured this imposition. Further examples indicated that the development of the ESP and the writing of its terms of reference involved donors, donor-hired consultants, and technical assistants as the experts from whom the MoE officials received "expert knowledge", a knowledge which aligned more often than not with the donor-initiated global policies (Moutsios, 2008, 2009). Through global programmes and policies that attracted donor funding and technical support, policies were transferred to Ghana through 'agenda-setting' approaches in transnational and supra-national contexts like the EFA goals and MDGs set under the leadership of donors in Jomtien in 1990 and Dakar in 2000 respectively. Moutsios $(2008,2009)$ asserted that what was considered a national policy success was no longer decided within national boundaries but in transnational contexts populated by international organisations. In this case global policies such as the MDGs and EFA goals encapsulated and predetermined the national such as the ESP, but it was within the national context that the former expanded (Beck 2005). Beck (2005) argued that it was primarily within the contexts of international organisations and not in national contexts that the principles of the power game of global policy were determined, approved, and remoulded. Like other studies, this paper argues that these principles not only altered fundamentally Ghana's national political and social processes but were also entrenched within their body politic through the foreign aid system (Callaghy, 1990; Hutchful, 1996; Kraus, 1991, 2002; Toye 1991; Whitfield, 2006). Thus, the development of the ESP witnessed a policy imposition, and therefore would be located at the end of the education policy transfer continuum labeled as involuntary influence (Phillips \& Ochs, 2004). Findings suggest that the contexts of the ESP influence and production reflected an obligatory imitation of policy and practice from foreign contexts (ibid.). In this case policy transfer occurred not through borrowing but imposition (ibid.).

This imposition has led to the view that the ESP shaping process in an aid recipient African country like Ghana illustrates globalisation as having colonial and imperial expressions. Similar to other studies, the findings of this study show that donor leverage was not only financial but also sometimes originating from imperial and colonial history (Abdi, 2006; Stromquist, 2002). The impact of globalisation on countries in sub-Saharan Africa has not often been beneficial (Petras, 1999; Stromquist, 2002). It is a complex phenomenon that has been made even more so by 
the effects of imperialism, neo-colonisation and neoliberalism, all of which have contributed to the dismantling of sovereignty and cooperative machinery (Abdi, 2006; Harvey, 2005; Odora Hoppers, 1999). As a result, the market, along with other hegemonic powers such as imperialism and (neo-) colonialism (in the case of sub-Saharan African countries), usurps states' control of education policy processes and differentially transforms their economic and political authority (Stromquist, 2002). While developed countries seem to benefit immensely from this alteration, the developing ones emerge as the losers as they experience imperialistic tendencies in their relations with the former (ibid.; Petras ,1999). ${ }^{3}$ For example, in Ghana, the World Bank with the support of the IMF and other donors like DFID, USAID and UNICEF prescribed the neo-liberal macro-economic policy framework in the form of a poverty reduction strategy known formerly as the Ghana Poverty Reduction Strategy (GPRS I) and later as the Growth and Poverty Reduction Strategy (GPRS II). These donor prescriptions included trade liberalisation measures that benefitted foreign-owned companies but weakened the economic freedom and growth of aid dependent countries (Stewart and Wang 2003; WDM 2005). In order for the MoE to qualify for donor funds it was imperative that the ESP, which was regarded by donors as a mechanism for the delivery of donor funds to the MoE, drew on GPRS I.

It is valid that the contestations that characterise the terrain of policy processes when nation states have autonomy do not differ dramatically from those that are occurring now with globalisation usurping states' control over national policies (Dale, 2007). However, the notion that a "difference between globalisation and imperialism/colonialism is that what once happened to only third world and colonized countries is now happening to the more powerful states, previously the initiators rather than the recipients of external pressures on their national policies" is debatable (Dale, 2007, p.54). This is because donor countries might equally be recipients of external pressures. Yet they remained not only the previous but also the present source of these pressures, and therefore, better placed to mitigate them for their own national benefit than most aid recipient African countries. According to Leach (1999), colonialism with its damaging repercussions is still very much alive. She states:

....t lives on in its new guise of multinational and global corporations; in northern hegemony over global political, economic, and technological developments; and in the international development agenda whereby aid agencies in the north hold a monopoly not only over accepted definitions of development, but also over the options and choices made available to resource-poor governments and individuals in the south. These agencies determine not only how development should be viewed but also how it should be shaped (Leach, 1999, p.372).

Although globalisation is a highly complex phenomenon that cannot be reduced to a single element, this study sees imperialism and colonisation as constitutive and lying at the core of globalisation. Although the findings of the present study did not explicitly draw direct links between imperial/colonial history and the leverage donors possessed over the MoE/GoG, they alluded to colonial or imperial history as the origin of a special relation between some donors and Ghana or the MoE/GoG. For example, to be able to influence the ESP shaping process significantly a donor had to occupy a special position in relation to the MoE/GoG or Ghana, and colonial history was one defining element of this "specialness". Findings suggest that an imperial historical link between a bilateral donor country and the recipient country was regarded as shaping the nature of interactions, which the donor regarded as special (Amoako, 2009).

Like Henry and colleagues this paper argues that "[at] the normative level...globalisation constitutes an emergent form of Western imperialism carried through cultural institutions such as education" (Henry et al. 2001, p.4). Although globalisation does not imply that the whole world has been 'Westernised', every arena of social existence ought to determine its stance with regards to the industrialised West. Unequivocally, the capitalist industrial West emerges as the measure for the policy choices of nations (Leach, 1999; Waters, 1995, p.3; ibid.). Since policy choices in countries like Ghana were made in a manner that should secure donor approval, the ESP process might seem to engender imperialistic tendencies.

In concluding this section, it is worth reiterating that the shaping of the ESP was influenced by globalisation through donors who were often its most powerful architects, drivers and agents. The production of the ESP indicated that the global policies or the non-negotiables such as the PRSPs, the EFA goals and the MDGs had to be adopted first by the MoE/GoG before it could qualify for donor support. The prompting that the MoE/GoG experienced from donors and the emphasis by the latter on the importance of the global dimension to the ESP were typical examples. These represented some of the interrelated effects generated by globalisation and revealed through the ESP formulation process. In attempting to analyse how globalisation has influenced education in the manner of scholars such as Stromquist (2002) and Dale (2007), this study has clarified some characteristics of globalisation and the power dynamics it generated in the shaping of the ESP. Global policies, the non-negotiables, which got embedded in the national policy, the ESP, exemplified the cultural hybridity that signified the effect of globalisation (Stromquist, 2002). Since globalisation processes are both ideological and material, its normative presumptions need to be confronted (ibid.). This essentially involves a political obligation to institute boundaries for 


\section{EMEFA AMOAKO}

education policy processes for national benefit (ibid.). These parameters must determine the pressures of global transformation while questioning the ideology of the neo-liberal notion of globalisation as a given (Henry et al., 2001).

The findings contribute to our understanding of the means by which an emergent global education policy field influenced a national education policy field, what Rawolle and Lingard (2008, p.733) refer to as the "cross field effects with national education policy field mediated by national capital". The shaping of the ESP was an illustration of these cross-field effects between the global policy field and a national policy field, which this paper referred to as the confluence. In other words, along with other factors globalisation shaped the environment within which the MoE-donor interactions and their formulation of the ESP occurred. The confluence guaranteed the global dimension of the ESP, which perhaps culminated in the shrinking, and misrepresentation, of the educational policy interests of the MoE/GoG. This was regarded as a process of policy imposition depicted through the expressions of globalisation as imperialistic. For this reason, there had been calls that it was imperative that such a confluence which shaped a national policy like the ESP, and accommodated the global-national policy interactions, should be underscored by the principles of country-led partnership.

\section{Significance of the Confluence and Concluding Remarks}

Education policy processes, particularly, in aid recipient countries have created a space for both external and internal agents to interact, which this paper calls the confluence, a point of connectedness where globalisation processes are rife. The confluence is where important national policies are shaped and implemented. It is hugely important and a significant opportunity for policy actors to explore this confluence with "a comparativecollaborative-reflective approach" (Tatto, 2011, p.510). Here, the role of comparative and international education is crucial. The realisation of its hegemonic dimension, hence calls to its agents to adopt democratic approaches, sensitises one to the sociology of absences, and the notion that silences do not just happen but are constructed (Santos 2005; Dale 2006). Thus, the confluence acknowledges the possible inequalities engendered by globalisation in policy processes. It encourages dialogue and mutual intelligibility between the multiple cultures and knowledges that both national and global policy agents bring to its space, which is similar to Santos' (2005) notion of translation. This has the potential to create opportunities for reciprocal learning between different policy actors, even if some are from dominant cultures interacting with those from the margins (the other / subaltern).

Like Santos' contact zones, understanding the confluence facilitates learning and reflection in education policy processes thereby creating less absences and silences. The aim is to eventually undermine marginalisation and voicelessness. The authority to determine the feasibility of knowledges, or the group that assigns recognition to them will not only be international/global but also national/local. In other words, this authority will not only be located within the dominant cultures but also at the peripheries. Hence the process of knowledge determination or recognition as legitimate or approved, what Bourdieu calls reconnaissance will assume much more democratic dimensions (Appadurai, 2001; Bourdieu, 1991; Dale, 2006; Robertson, 2006; Santos, 2005). In this way, agents of comparative and international education involved in policy or research processes will gain the opportunity to enrich, and not deplete their experiential coffers.

Acknowledging the policy process as a confluence promotes increased sensitivity to culture and context, and helps to stem the tide of uncritical transfers of globally dominant models to national policy spaces. Adopting this stance will incline both external and internal policy makers and implementers to acknowledge the complex processes of globalisation (including partnership, funding/foreign aid, policy and power), and attempt to devise ways to explore these processes to the advantage of the policy beneficiaries. Nevertheless, the notion of the confluence is still to be regarded a "situated knowledge" that is partial and therefore, must constantly lend itself to rigorous critical examination of and reflection on its processes (Haraway, 1988). Overall though, I argue that the confluence is an essential construct worth engaging with in education policy processes (and perhaps in research processes) within the context of comparative and international education.

\section{Notes}

${ }^{1}$ In employing snowballing, most of the respondents helped in identifying other relevant respondents, especially when it was difficult to identify relevant key people (Robson, 1993). In the case of theoretical sampling, sampling was done on the basis of ideas that had established theoretical significance to the developing theory of MoE-donor interactions and their shaping of the ESP (Strauss \& Corbin, 1990: 177).

2 See Stromquist (2002) for a more comprehensive definition of globalisation in relation to education.

${ }^{3}$ There is no doubt that globalisation creates vulnerable populations in the developed world too. However, the potential to mitigate the social costs it incurs within this context is stronger than in aid dependent African countries. This is due to the fact that developed nations are powerfully positioned economically and politically. 


\section{References}

Abdi, A.A. (2006). Culture of education, social development, and globalisation: Historical and current analysis of Africa. In A.A. Abdi, K.P. Puplampu \& G.J.S. Dei (Eds.) African education and globalisation: Critical perspectives. Lanham: Lexington.

Amoako, E.J.A. (2009). Shaping policy at the confluence of the global and national: Ghana's Education Strategic Plan. Unpublished D.Phil. thesis. UK: University of Oxford.

Appadurai, A. (2001). Grassroots globalization and the research imagination. In A. Appadurai (Ed.) Globalization. Durham: Duke University Press.

Apple, M. (1989). Critical introduction: Ideology and the state in educational policy. In R. Dale (Ed.) The state and education policy. Milton Keynes: Open University Press.

Ball, S.J. (1994). Education reform: A critical and post-structural approach. Buckingham: Open University Press.

Beck, U. (2005). Power in the global age: A new global political economy. London: Polity.

Bourdieu, P. (1991) Language and Symbolic Power, J.B. Thompson (Ed.). Oxford: Polity Press.

Bowe, R., Ball, S.J. \& Gold, A. (1992). Reforming education and changing schools. London: Routledge.

Callaghy, T. (1990). Lost between state and market: The politics of economic adjustment in Ghana, Zambia and Nigeria. In J. Nelson (Ed.), Economic crisis and policy choice: The politics of adjustment in the Third World. Princeton: Princeton University Press.

Cornell, R. (2007). Financing development: Aid and beyond. OECD Publishing.

Dale, R. (1989). The state and education policy. Milton Keynes: Open University Press.

Dale, R. (1999). Specifying global effects on national policy: A focus on the mechanisms. Journal of Education Policy, 14, 1-7.

Dale, R. (2006). From comparison to translation: Extending the research imagination? Globalisation, Societies and Education, 4(2), 179-192

Dale, R. (2007). Specifying globalization effects on national policy: A focus on the mechanisms in B. Lingard and J. Ozga (Eds.). The RoutledgeFalmer Reader in Education and Politics. London and New York: Routledge.

Elson, D. \& McGee, R. (1995). Gender equality, bilateral program assistance and structural adjustment: Policy and procedures'. World Development 23(11), 1985-1994.

Government of Ghana \& Ministry of Education (GoG/MoE). (2003). Education Strategic Plan 2003 to 2015 Vol.1: Policies, targets and strategies. Accra: Ministry of Education.

Haraway, D. (1988). Situated knowledges: The science question in feminism and the privilege of partial perspective. Feminist Studies, 14(3), 575-599.

Harvey, D. (2005). A brief history of neoliberalism. Oxford: Oxford University Press.

Henry, M., Lingard, B., Rizvi, F. \& Taylor, S. (2001). The OECD, globalisation and education policy. Oxford: Elsevier Science Ltd.

Hutchful, E. (1996). Ghana 1983-94. In P. Engberg-Pedersen et al., Limits of adjustment in Africa: The effects of economic liberalization. Oxford: James Currey.

Hutchful, E. (2002). Ghana's adjustment experience: The paradox of reform. Oxford: James Currey.

International Working Group on Education (IWGE). (1999). Disadvantage, dialogue and development Co-operation in education: A report from the IWGE. Paris: UNESCO/IIEP.

Jones, P.W. \& Coleman, D. (2005). The United Nations and education: Multilateralism, development and globalisation. Abingdon, UK: RoutledgeFalmer.

King, K. (2007). Balancing basic and post-basic education in Kenya: National versus international policy agendas. International Journal of Educational Development, 27(4), 358-370.

Kraus, J. (1991). The political economy of stabilization and structural adjustment in Ghana. In D. Rothchild (Ed.), Ghana: The political economy of recovery. London: Lynne Rienner.

Kuder, J. (2005). UPE in Tanzania: SWAP-ing quality for quantity - Again? Globalisation, Societies and Education, $3(2), 165-181$.

Leach, F. (1999). Dilemmas between economics and culture in educational aid: Lessons for donors. In F. Leach \& A. Little (Eds.) Education, cultures, and economics: Dilemmas for development. London: RoutledgeFalmer.

Lingard, B. (1996). Review essay: Educational policy making in a postmodern state. On Stephen J. Ball's education reform: A critical and post-structural approach. Australian Educational Researcher, 23(1), 65-91.

Lingard, B., Rawolle, S. \& Taylor, S. (2005). Globalising policy sociology in education: Working with Bourdieu. Journal of Education Policy, 20(6), 759-777.

Lingard, R. \& Ozga, J. (2007). Reading education policy and politics. In R. Lingard \& J. Ozga, J. (Eds.) The Routledge Falmer reader in education policy and politics. London: Routledge. 


\section{EMEFA AMOAKO}

Little, A. (2008). EFA, politics, policies and progress: Research Monograph No. 13. Brighton, UK: CREATE, University of Sussex.

Lukes, S. (2005). Power: A radical view. Basingstoke: Palgrave Macmillan.

Merriam, S.B. (1988). Case study research in education: A qualitative approach. San Francisco: Jossey Bass.

Moutsios, S. (2008). International organisations and transnational education policy. Compare: $A$ Journal of Comparative and International Education, 39(4), 1-12.

Odora Hoppers, C. (1999). The morning after midnight? Partnerships and paradigms for development cooperation in the $21^{\text {st }}$ Century. Northern Policy Research Review and Advisory Network on Education and Training (NORRAG). 25 December, pp. 19-20.

Ozga, J. (1990). Policy research and policy theory: A comment on Fitz and Halpin. Journal of Education Policy, 5(4), 359-362.

Petras, J. (1999). Globalization: A critical analysis. Journal of Contemporary Asia, 29(1), 3-37.

Phillips, D. \& Ochs, K. (2004). Researching policy borrowing: Some methodological problems in comparative education. British Educational Research Journal, 30(6), 773-784.

Punch, K.F. (1998). Introduction to social research: Quantitative \& qualitative approaches. London: Sage Publications.

Rawolle, S. \& Lingard, B. (2008). The sociology of Pierre Bourdieu and researching education policy. Journal of Education Policy 23, 729-740.

Robertson, S.L. (2006). Absences and imaginings: The production of knowledge on globalisation and education. Globalisation, Societies and Education, 4(2), 303-318.

Robson, C. (1993). Real world research. Oxford: Blackwell.

Robson, C. (2002). Real world research: A resource for social-scientists and practitioner researchers. 2nd Edition. Oxford: Blackwell.

Santos, B. S. (2005). The future of the World Social Forum: The work of translation. Development, 48(2), $15-22$.

Strauss, A. \& Corbin, J. (1990). Basics of qualitative research: Grounded theory procedures and techniques. Newbury Park, CA: Sage.

Stewart, F. \& Wang, M. (2003). Do PRSPs empower poor countries and disempower the World Bank, or is it the other way round? QEH Working Paper Series- QEHWP 108. Oxford: Queen Elizabeth House (QEH), University of Oxford.

Stromquist, N.P. (2002). Education in a globalized world: The connectivity of economic power, technology, and knowledge. New York: Rowan \& Littlefield Publishers, Inc.

Takyi-Amoako, E. (2012). Comparing power spaces: The shaping of Ghana's Education Strategic Plan. Compare: $A$ Journal of Comparative and International Education, 42(1), 113-135.

Tatto, M.T. (2011). Reimagining the education of teachers: The role of comparative and international research. Comparative Education Review, 55(4), 495-516.

Taylor, S., Rizvi, F., Lingard, B. \& Henry, M. (1997). Educational policy and the politics of change. London: Routledge.

Taylor, S. \& Henry, M. (2000). Globalisation and education policymaking: A case study. Educational Theory, 50(4), 487-503.

Toye, J. (1991). Ghana. In P. Mosley, J. Harrigan \& J. Toye (Eds.). Aid and power: The World Bank and policy-based lending. London: Routledge, pp. 150-200.

Vidovich, L. (2001). A conceptual framework for analysis of education policy and practices. Paper proposed for presentation at the Australian Association for Research in Education, Fremantle, December 2001.

Waters, M. (1995). Globalization. London: Routledge.

World Development Movement (WDM). (2005). 9 out of 10 World Bank poverty reduction programmes demand privatisation. Available at http://www.globalpolicy.org/socecon/bwiwto/wbank/2005/0919ipocri.ht (Accessed 18 October 2005).

Whitfield, L. (2006). Aid's political consequences: The embedded aid system in Ghana - GEG Working Paper 24. Oxford: Global Economic Governance Program. 